\section{Resumen}

Este artículo pone en discusión algunas reflexiones sobre las concepciones en torno de la equidad y la justicia de niños y niñas de 8 a 10 años, y sobre su carácter central en los procesos de configuración de subjetividad política. Estas reflexiones se han ido perfilando en el marco de un proceso de socialización política: el proyecto "Niños y niñas, constructores y constructoras de paz", desarrollado desde 1998, con la participación activa de niños y niñas de 80 escuelas públicas de sectores de gran conflictividad social, tanto en su diseño, como en su puesta en marcha, su seguimiento y su evaluación. Ha tenido como propósito construir, teniendo como punto de partida las propias maneras de comprender la justicia por parte de los niños y las niñas, y con su participación activa, una propuesta educativa de construcción de paz, como proceso de socialización política, centrada en el fortalecimiento de la subjetividad política, que se articula alrededor de varios ejes entrecruzados de manera compleja en un entramado de posibilidades: potencial afectivo, potencial creativo, potencial ético-moral y potencial político. Las concepciones de justicia se analizan desde tres perspectivas: la social y cultural; la jurídica y moral; y la política, evidenciando la necesidad de su reconfiguración para poder enfrentar un proceso de socialización política que realmente conduzca a subjetividades políticas favorables a la democracia. Para la configuración de la subjetividad política en niños y niñas, la socialización política juega un papel trascendental, en tanto crea o hace visibles las oportunidades y las condiciones en las cuales niños y niñas pueden recuperar y explicitar el sujeto político, que en nombre de su minoridad, su vulnerabilidad y su incapacidad, les ha sido arrebatado en las tramas sociales de este orden social tan poco democrático que en nuestros países latinoamericanos se denomina hoy "democracia".

Palabras clave:

Subjetividad política, concepciones de equidad y justicia, socialización política, democracia.

\section{Abstract}

This article aims at submitting some reflections about the conceptions dealing with equity and justice by children from 8 to 10 years old, and with their main characteristics in the processes aiming at structuring political subjectivity. These reflections have been consolidating from the perspective of a political socialization process: the project entitled "Niños y niñas, constructores y constructoras de paz" ("Boys and girls as peace constructors"). This project has counted on the participation, through its various stages, of boys and girls from 80 public schools located in districts of dense social conflicts. The project started in 1998 and the girls and boys have participated in its design, implementation, follow-up and evaluation. Its goal has been to consolidate, taking into consideration the boys and girls' own ways of understanding justice and their participation as the point of departure, an educational proposal for the construction of peace as a political socialization process. This process is based upon the strengthening of political subjectivity that articulates itself around various interconnected axes to form a complex network of possibilities: affective, creative, ethical-moral and political potentials. The conceptions about justice are analyzed from three perspectives: social and cultural, juridical and moral as well as political; thus showing the need for their restructuring to confront a political socialization process that can actually result in political subjectivities favoring democracy. Political socialization plays a crucial role in the structuring of the political subjectivity of boys and girls as it creates or makes visible the opportunities and conditions through which they can recover and explicit the political subject they have lost because of minority, vulnerability and incapacity, by means of the poorly democratic networks of social signification that is known as "democracy" in our Latin-American countries.

Key words:

Political subjectivity, conceptions dealing with equity and justice, political socialization, democracy. 


\title{
INVESTIGACIONES \\ Las concepciones de equidad y justicia en niños y niñas: desafíos en los procesos de configuración de la subjetividad política*
}

\author{
Sara Victoria \\ Alvarado Salgado \\ Héctor Fabio \\ Ospina Serna²
}

\section{Introducción}

Este artículo pone en discusión de la comunidad académica algunas reflexiones sobre las concepciones en torno de la equidad y la justicia de niños y niñas de ocho a diez años de edad, y sobre su carácter central en los procesos de configuración de subjetividad política. Estas reflexiones se han ido perfilando en el marco de un proceso de socialización política: el proyecto Niños y niñas constructores y constructoras de $p a z^{3}$, desarrollado desde 1998, con la participación activa de niños y niñas, tanto en su diseño, como en su puesta en marcha, su seguimiento y su evaluación. El proyecto ha sido desarrollado en cerca de 80 escuelas públicas ubicadas en sectores urbanos de gran conflictividad social en diferentes departamentos de Colombia y ha tenido como propósito construir, teniendo

\footnotetext{
* Este artículo fue escrito con base en resultados parciales del proyecto de investigación que se desarrolló del 22 de febrero de 2002 al 5 de noviembre de 2004 cofinanciado por Colciencias (código 1235-10-11201), el CINDE, la Universidad de Manizales y Save The Children U. K.: Concepciones políticas y transformación de actitudes frente a la equidad en niños y niñas de sectores de alto riesgo social del Eje Cafetero, y desarrollado por el equipo de investigación conformado por Sara Victoria Alvarado y Héctor Fabio Ospina, como investigadores principales, María Teresa Luna y Marina Camargo, como investigadoras asistentes, y Luis Guillermo Jaramillo, Julián Loaiza, Victoria Forero, Olga Porras y Nancy Puerta, auxiliares de investigación. Este equipo pertenece a las líneas de investigación "Socialización política y construcción de subjetividad" y "Educación y pedagogía", del grupo de investigación reconocido por Colciencias en categoría A: Actores, escenarios y procesos del desarrollo humano de la niñez y la juventud, perteneciente al Centro de Investigaciones y Estudios Avanzados en Niñez y Juventud, del CINDE, y la Universidad de Manizales. El grupo de investigación agradece la participación de las ocho instituciones educativas y sus profesores comprometidos en el proceso. Texto recibido en mayo 2 de 2006 y arbitrado en mayo 10 de 2006.

${ }^{1}$ Doctora en educación. Directora de la línea de investigación en socialización política y construcción de subjetividad. Profesora del doctorado en Ciencias Sociales, Niñez y Juventud, Universidad de Manizales-CINDE. doctoradocinde@umanizales.edu.co

${ }^{2}$ Doctor en Educación. Director de la línea de investigación en educación y pedagogía. Profesor del doctorado Ciencias Sociales, Niñez y Juventud, Universidad de Manizales-CINDE. revistacinde@umanizales.edu.co

${ }^{3}$ El proyecto Niños y niñas constructores de paz está implementándose en Colombia desde 1998 por parte del Centro de Estudios Avanzados en Niñez y Juventud, del Cinde, y la Universidad de Manizales, con el apoyo de Save the Children, Unicef, Fundación Antonio Restrepo Barco y Children of the Andes. Actualmente el proyecto se trabaja además con jóvenes, con el apoyo de Plan Internacional y ACDI, de Canadá.
} 
como punto de partida las propias maneras de comprender la justicia por parte de los niños y las niñas, y con su participación activa, una propuesta educativa de construcción de paz, como proceso de socialización política, centrada en el fortalecimiento de la subjetividad política, desplegada en el potencial humano afectivo, creativo, ético y político de los niños y las niñas (Ospina y Alvarado, 2001).

A juicio de los autores, la configuración de una subjetividad política de niños y niñas que habitan contextos violentos como el colombiano, se articula alrededor de varios ejes que se entrecruzan de manera compleja. Hemos denominado a estos ejes así:

a) Potencial afectivo, entendido como capacidad de equidad y aceptación activa de la diferencia, que tiene en su base la configuración de nuevos sentidos en los cuales niños y niñas puedan reconocerse a sí mismos, reconocer a otros, dar y recibir afecto, consolidando redes de interacción en las cuales se acepte y se valore la diferencia, en condiciones de equidad.

b) Potencial creativo, entendido como el uso de la razón, del pensamiento, de la capacidad de generar ideas, para identificar y entender las raíces de los conflictos y generar alternativas dialógicas para su resolución que permitan una convivencia pacífica basada en el reconocimiento y no en la dominación.

c) Potencial ético-moral, entendido como la aceptación concertada de ciertos marcos ético-morales de regulación de la intersubjetividad: la justicia, fundamentada en la equidad; el respeto, configurado desde el reconocimiento, y la responsabilidad, basada en la solidaridad y en la cooperación.

d) potencial político, entendido como la configuración de niños y niñas, con ciudadanía plena, sujetos políticos, autónomos, reflexivos, participando en procesos de construcción democrática en sus contextos primarios de actuación: la familia, la escuela y el barrio.

Para la configuración de la subjetividad política en niños y niñas, la socialización política juega un papel trascendental, en tanto crea o hace visibles las oportunidades y las condiciones en las cuales niños y niñas pueden recuperar y explicitar el sujeto político, que en nombre de su minoridad, su vulnerabilidad y su incapacidad, les ha sido arrebatado en las tramas de este orden social tan poco democrático en nuestros países latinoamericanos. 


\section{Algunos tránsitos necesarios para reflexionar sobre el niño y la niña como sujetos políticos}

\subsection{La superación del sujeto cartesiano: ¿muerte o reconfiguración del sujeto?}

Desde el imaginario moderno, la categoría "sujeto" se define desde tres supuestos: la separación, el sustancialismo y el ideal de perfección (Maffesoli, 2004), características que se manifiestan en el "sujeto" de Descartes (cogito ergo sum: individuo que piensa por sí mismo) y en el carácter autónomo que le imprimió Rousseau (autónomo en griego significa: "yo soy mi propia ley"). Se define el sujeto poniendo toda la fuerza en su razón y en el lenguaje con que se nombra lo que pasa por la razón. De esta manera, la categoría sujeto ha ido saturándose de discurso, de lenguaje, pero quedando vacía en tanto desde la separación, el sustancialismo y los ideales de perfección, se ha ido perdiendo su realidad. El sujeto racional separado del otro, del mundo, de sus propias mediaciones; es decir, el sujeto trascendental kantiano, el sujeto cartesiano, deviene en sujeto vacío, sin historia, sin concreciones. El sujeto racional sustancia es sujeto cosificado, objetivado, alienado, que pierde su historicidad, su acción, su impermanencia, su transformación. El sujeto racional que se define desde ideales de perfección pierde su propia naturaleza tensional, conflictiva, vital, compleja.

El hecho de que la categoría sujeto esté saturada de discurso, y por tanto las maneras de nombrarla estén gastadas, (concretamente, en la dimensión de la política, ciudadano, justicia, equidad, democracia, votante, representante, actor social, participante deliberativo, etc.), no quiere decir que no existan individualidades y formas de interacción entre ellas que necesiten ser "re-nombradas" y resignificadas, atendiendo más a sus propias realidades, que a las abstracciones formales enunciadas desde los ideales de perfección de la modernidad. Estas realidades tienen un carácter múltiple: los individuos, los niños, las niñas y sus relaciones, además de cognición-razón, son sensibilidad, cuerpo, emociones, anhelos, tradiciones, sentimientos; es decir, son historia en construcción, son experiencia vital. Se trata entonces de enfatizar en la "enteridad" to, de los niños, de las niñas, mirada no desde su sustancia, sino desde su experiencia vital impermanente, transformadora, compleja, conflictiva e imperfecta, y esta experiencia siempre es con otros, en referencia a otros o por otros.

La enteridad implica el paso del individualismo a la persona, el morirse a sí mismo como individuo para encontrarse en un sí mismo más amplio, el del nosotros; un nosotros que además habita una sociedad fragmentada, desregulada y estructuralmente fracturada (Martín-Barbero, 2004). No esa sociedad

\footnotetext{
${ }^{4}$ Retomamos de Michael Mafessoli (2004) el concepto de enteridad como expresión de la totalidad del sujeto en su complejidad, no el sujeto-razón, sino el sujeto en sus múltiples dimensiones (cuerpo, emoción, sentimiento, razón, etc.), y en sus múltiples condiciones identitarias.
} 
racional del ideario moderno, nombrada como tal en el siglo XIX y que remite al concepto del contrato social. La superación de este sujeto trascendental, del individualismo que está en su base, y de esa sociedad racional, nos ponen frente a la instauración de múltiples yoes y de diversas maneras de relación; es decir, nos abocan al surgimiento de la enteridad y de la pluralidad como superaciones de la separación, el sustancialismo y el ideal de perfección del sujeto y de la sociedad en el ideario moderno. En esos múltiples yoes habitan a su vez múltiples condiciones identitarias, que hacen que en la vida cotidiana el sujeto-niño-niña se exprese como realidad compleja, tensional y en muchas oportunidades contradictoria y fragmentada, yoes con pertenencias diversas en colectivos desregulados (nosotros), que se corresponden mucho más con una realidad diversa, vital y compleja que con el concepto de una sociedad regulada por un acuerdo o pacto (contrato social), que no pasa de ser un ideario normativo cuyas expresiones históricas reales se explicitan en grandes distorsiones.

Con lo anterior no se quisiera negar la importancia de los acuerdos sociales de convivencia y regulación social. Se quiere enfatizar en la necesidad de recuperar un sujeto capaz de autoproducirse, al mismo tiempo que produce el mundo social y sus universos de sentido (Berger y Luckman, 1983, 1995), un sujeto que sólo puede configurarse desde sus propias maneras de ver, pensar y sentir el mundo, al otro, su realidad; es decir, de sus propios sentidos, que van reconfigurándose en su autoproducción.

\subsection{La subjetividad política:}

desarrollo del potencial del ser humano como constructor de historia

Construir historia, construir el mundo social y configurar sus universos de sentido se constituye así, en un proceso complejo, en tanto participan diferentes colectivos sociales que coexisten y emergen y pierden visibilidad en diferentes momentos y espacios, logrando mayores o menores influencias, desde la adhesión, la oposición o la resistencia, desde diferentes maneras de pensar y sentir sobre lo que es justo o injusto; movimientos conformados por sujetos con múltiples identidades fragmentadas que transitan entre su vida cotidiana en la construcción de su historia personal y su participación en macroprocesos vinculados, con mayor o menor conciencia en la construcción de la historia de sus localidades, de su país (Zemelman, 2004).

A pesar de lo anterior, la pregunta que surge, al reflexionar sobre la subjetividad política, es: ¿por qué, a pesar del potencial para actuar en la historia, en la construcción de país, las personas nos enclaustramos en el ámbito de lo privado y dejamos que el país sea construido por otros? ¿Qué es lo que hace que la frustración y la desesperanza sean los sentimientos que definen la decisión final de las personas para vincularse o no a la construcción de país? Zemelman (2004) propone como hipótesis la definición de factores encubridores del verdadero repliegue del sujeto sobre sí mismo y sobre sus relaciones primarias: la ignorancia, el miedo, la apatía y el aislamiento. Éstos son factores que bloquean, que atrapan al yo, que 
le impiden pensar y actuar, tener posturas claras y voluntad real de construcción con otros, que configuran subjetividades pasivas, conformistas, acríticas, no lúcidas; es decir, según Agnes Heller (citada por Zemelman, 2004), subjetividades subalternas; es decir, subjetividades sin un sujeto real que las habite.

Se requieren, en los procesos de socialización política, paradigmas que rompan el miedo, la apatía, la incredulidad y el escepticismo frente a la posibilidad de pensar y construir futuros, por parte de los agentes socializadores, y de los niños y las niñas; es decir, que se hace necesario, según Zemelman (2004), recuperar o activar el sujeto, pero no el sujeto cartesiano, sino el sujeto en su enteridad: el sujeto con su conocimiento, con sus concepciones sobre lo justo y lo injusto, con su capacidad de pensar críticamente, con sus emociones y sus sentimientos para involucrarse en el destino de los otros, y con su voluntad personal, para enfrentarse a su propio yo, para actuar con otros, para romper los muros de la vida privada y encontrar sentido en la construcción política en los escenarios de acción colectiva. La recuperación del sujeto en su enteridad pasa por la recuperación de sus verdaderos sentidos, no los de un sujeto abstracto, sino los de sujetos de carne y hueso, hombres y mujeres, niños y niñas, que habitan momentos históricos complejos que deben saber leer, entender e intervenir. Por eso la socialización política, como escenario privilegiado de formación, debe pasar por el conocimiento a fondo de sí mismo, desde sus propias posibilidades y límites, y por el conocimiento de las realidades donde se vive y por sus expresiones simbólicas, porque es allí donde se encuentran las posibilidades de acción y los nuevos sentidos que pueden ir construyéndose; el sujeto se define por la posibilidad de una producción de sentidos que abre espacios singulares, dentro de contradicciones con otros espacios (González, 2002).

La recuperación del sujeto en su enteridad pasa también por la recuperación de su autonomía, entendida ésta no como mera retórica, ni como metáfora, ni como discurso vacío, discurso sin sujeto. Se trata de recuperar su "capacidad de pensar por sí mismo, sin desconocer al otro, y reconocer, crear, disponer en la práctica los principios que orientan la vida" (Cubiles, 2004, p. 124). La autonomía ha sido vista como un logro juvenil o de los adultos. En el proyecto Niños y niñas constructores y constructoras de paz le hemos apuntado a pensar en la capacidad real que pueden tener los niños y las niñas para actuar con otros, niños o adultos, desde sus propias posturas frente a lo justo y lo injusto, construidas desde su capacidad de pensar, desde sus emociones y desde su voluntad personal, en sus escenarios de actuación cotidiana.

Esta propuesta de socialización política incorpora el análisis de las coyunturas en las cuales niños y niñas pueden reconocerse como constructores y constructoras de su realidad, "es la idea de coyuntura como el momento que lleva a la idea de un presente en el que los hombres pueden actuar" (Zemelman, 2004, pp. 103-104). Esta coyuntura, este presente, no es entendido como la negación de la historia, sino como la expresión de lo que ha sido construido en el pasado en su ámbito familiar, escolar y barrial, y en 
escenario de construcción del futuro, no como utopía irrealizable, sino como proyecto político conjunto, complejo y diverso en el cual se juegan las subjetividades políticas de niños y niñas en sus contextos de actuación.

\subsection{La socialización política:}

\section{un escenario posible de construcción de subjetividad política}

La socialización política como proceso formativo de las subjetividades políticas, en el contexto colombiano, no puede darse por fuera de las preguntas básicas sobre la equidad y la justicia social, la ampliación de la democracia y el fomento del ejercicio ciudadano (Cubiles, 2004); sobre los procesos de construcción de paz, en su acepción de paz positiva ${ }^{5}$ (Jarés, 1999); sobre las condiciones de inclusión y reconocimiento social (Fraser, 2003). La formación de subjetividades políticas de niños y niñas implica la formación de su ciudadanía plena, el crear las oportunidades y condiciones para que niños y niñas puedan reconocerse como protagonistas de su propia historia, capaces de pensar, de interactuar con otros en la construcción de proyectos colectivos orientados al bien consensuado, con espíritu crítico y capacidad de autorreflexión para leer su propia historia y la de su realidad, y con apoyo a su cultura de pertenencia y apropiación de los significados culturales de los colectivos a los cuales pertenece (su escuela, su familia, su grupo de pares, su cultura, su etnia, etc.); es decir, se trata de ayudar a potenciar en ellos y en ellas como sujetos políticos, una nueva manera de pensar, de sentir y de ser sujeto desde la autonomía.

Formar la subjetividad en este sentido significa desplegar la singularidad subjetiva, "abrir las vías para que los individuos se desarrollen desde sus propias coordenadas existenciales, desplegando sus capacidades a partir de una autorreferencia subjetiva; es decir, de la reflexión sobre su propia libertad" (Cubiles, 2004, p. 119); pero entendiendo que la subjetividad singular sólo se construye en el marco de procesos de concertación y de interacción que involucran otras múltiples subjetividades igualmente ricas y complejas. La construcción de subjetividades singulares y su interacción con otras subjetividades en la cual se desdibujan los límites entre el yo y el otro, se da sólo en la experiencia, no en los discursos vacíos de sujeto; experiencia en la que confluyen las individualidades, la socialidad y los marcos simbólicos de la cultura, experiencia que se realiza en un presente que permite integrar la dimensión del pasado como cosmovisión y la de futuro como mixtura de expectativas, proyecciones y horizonte posible de obra colectiva (Zemelman, 2004), en la medida en que la experiencia pase por la reflexividad.

La reflexividad apunta a la ampliación de la dimensión política de la subjetividad por que implica una ubicación de la interacción humana en la esfera de lo público en la cual puede definirse el "sentido común" como pluralidad de

\footnotetext{
${ }^{5}$ La paz positiva es entendida no como la ausencia de violencia, sino como la construcción de condiciones democráticas de interacción social y participación. Reconoce el papel activo del conflicto como consubstancial a los procesos de interacción humana.
} 
intereses, pensamientos y voluntades de acción. Pero la subjetividad política se realiza finalmente en el campo del actuar, de un actuar colectivo para el logro de lo consensuado como "sentido común". Si bien la reflexividad en los niños y las niñas, puede no alcanzar grados tan altos de abstracción, como los alcanzados por jóvenes y adultos, no quiere decir que ellos y ellas no tengan la capacidad de pensar sobre su historia, sobre su contexto, sobre las condiciones en las que transcurre su vida, ni quiere decir que no tengan valoraciones racionales sobre lo justo y lo injusto y adhesiones afectivas frente a ciertos marcos simbólicos de acción de sus pares, sus padres, sus maestros, y aun de personas de la vida pública distantes a sus contextos de actuación social en la vida cotidiana.

La reflexividad tiene que ver con la posibilidad de decidir y actuar en los contextos sociales en los que niños y niñas, y todos aquellos con quienes interactúan, se involucran; y con las "formas de compartir el poder" (Cubiles, 2004, p. 122) en dichos contextos. La acción política en los escenarios infantiles de actuación implica la transformación del poder: del "poder" del adulto (padres, maestros) "sobre" los niños y las niñas, al "poder con" ellos y ellas, porque sólo en el "entre" se gana la posibilidad de un espacio en común; es decir, de un espacio público; y este espacio público es, precisamente, el escenario de la construcción de ciudadanía, de configuración de la subjetividad política. Este actuar conjunto es complejo, conflictivo y asimétrico, lo cual lleva a que aun en el terreno de la sociedad civil, en instituciones que de modo regular o tradicional estuvieron "al margen" de la política, como la familia y la escuela, temas culturales se tornen en temas de debate y participación en búsqueda del respeto a los derechos, y muchas de estas acciones se dan, precisamente por su carácter cultural, en el terreno de lo simbólico.

La acción política de niños y niñas es una acción creativa que busca reconfigurar tanto los órdenes institucionales (familiar, escolar) como los discursos sobre ellos a partir de nuevas formas de valorar; implica visibilizar tanto los discursos como las prácticas sociales que niños y niñas privilegian en su construcción de cotidianidad, que de manera implícita o explícita contienen un sentido de sociedad, de lo justo y lo injusto, es decir, una apuesta política frente a su realidad, que contiene necesariamente un proyecto de comunidad o de construcción colectiva.

\subsection{La participación infantil: \\ una condición y una oportunidad para configurar subjetividad política en procesos de socialización política}

La configuración de la subjetividad política en niños y niñas encuentra una de sus condiciones y oportunidades en los procesos participativos que partiendo realmente de lo que ellos y ellas piensan y de sus maneras infantiles de actuación, transforman las relaciones de poder entre adultos y niños y niñas basándolas en la cooperación, el respeto y la equidad; estos procesos participativos generan mayores posibilidades para que niños y niñas puedan fortalecer sus potenciales afec- 
tivo, creativo, ético-moral y político y tener mejores condiciones para construir procesos de interacción justos y equitativos, tanto en su vida cotidiana como en aquellos contextos más amplios que en un sentido u otro afectan sus maneras de relacionarse socialmente (Hart, 2000, 2004a, 2004b) $)^{6}$.

Muchos estudios con niños y niñas resaltan su capacidad para asumir roles significativos en los procesos de participación, a través de los cuales agencian nuevos sentidos y dan origen a nuevas prácticas, familiares, escolares y sociales; se muestra además cómo se logra esto en el marco de programas en los cuales se reconocen sus derechos y sus responsabilidades y se tienen en cuenta sus puntos de vista sobre lo justo y lo injusto; es decir, en aquellos programas desarrollados con criterios democráticos, de equidad, de inclusión y de reconocimiento al mundo infantil y a sus imaginarios sociales que circulan en sus formas de pensar, de legitimar, de valorar, de relacionarse con otros y de actuar (Woodhead, 1997, 1998; Lansdown, 2001; Cussianovich y Márquez, 2002).

En los procesos organizados de participación infantil, los niños y las niñas reconocen la injusticia presente en sus contextos de actuación en las distintas formas de discriminación y de falta de reconocimiento presentes en la inequidad social, de género, de etnia; en la intolerancia ante las diferencias de pensamiento, de religiosidad; en el uso del poder para dominar y maltratar, etc. De esta manera, asumen un mayor control sobre su vida y participan en la construcción de cambios sociales sostenibles, en los ámbitos civil y político, basados en interacciones pacíficas y equitativas (Short y Carrington, 1991; Hart, 1992, 1997, 2000; Hart y Schwab, 1997; Veloso, 2003; Ackerman et al., 2003; Liao, 2003).

\section{Las concepciones de equidad y justicia de los niños y las niñas: sus implicaciones en la configuración de su subjetividad política}

Además de los procesos participativos infantiles a través de movimientos organizados en diversas propuestas de socialización política, como aquellas a las que se ha hecho alusión en los estudios mencionados y en la propia experiencia del proyecto Niños y niñas constructores y constructoras de paz, la conformación de las concepciones de los niños y las niñas en torno de la equidad y de la justicia, categorías que estarían en la base de una subjetividad política favorable a la democracia, va dándose en procesos de socialización latente (Chaffe, Morduchowtz y Galperin, 1997). Dichos procesos se dan, tanto en los contextos directos de actuación de los niños y las niñas (familia, escuela, barrio), de acuerdo con las maneras de interrelación padres-hijos, hermano-hermana, hermana-hermana, maestro-alumnos, entre pares, etc.; como en el contexto social y político más amplio, en el cual los niños y las niñas se involucran, a través de los medios de comunicación, valorando y legitimando ciertos sentidos y prácticas particulares.

\footnotetext{
${ }^{6}$ Hart concluye en este sentido a partir de sus estudios comparativos sobre participación infantil realizados en Nepal, Sierra Leona y los
} territorios ocupados de Palestina. 
Aunque algunos estudios muestran cómo en las instituciones primarias, familia y escuela, los padres y los maestros juegan un papel importante en la conformación de las concepciones de los niños y las niñas en torno de la equidad y la justicia, ayudando a desarrollar una posición frente al mundo basada "en el cuidado" y en un sentido de responsabilidad por participar en la construcción de un mundo más equitativo y justo (Jannings y O’keefe, 2002); en un plano más amplio, las formas de organización de la sociedad civil impactan las propias posiciones de niños, niñas y jóvenes que se expresan en sus concepciones políticas de ciudadanía o justicia más referidas a los ámbitos locales, como contextos de actuación directa, que al contexto nacional (Collomb y Natalie, 2003). En nuestra última investigación ${ }^{7}$ los resultados nos ayudaron a comprender que las concepciones de equidad y justicia de nuestros niños y niñas ${ }^{8}$ presentan un entramado complejo, influido fuertemente tanto por la familia y la escuela como por la apropiación que ellos y ellas hacen del análisis que los medios de comunicación social hacen sobre la situación de conflicto del país y sobre las maneras de tramitar dichos conflictos.

Según Alvarado et al. (2005), las respuestas de los niños y las niñas que participaron en los talleres y en los grupos de discusión en la investigación permiten clasificar sus concepciones frente a la justicia en tres grandes perspectivas: socialcultural (59\%), jurídico-moral $(28 \%)$ y política $(13 \%)$.

En la perspectiva social y cultural el $80 \%$ asocia la justicia con la equidad como reconocimiento al "otro" en las relaciones cotidianas, por respeto a la dignidad humana y por rechazo a la discriminación. El 20\% restante asocia la justicia con la equidad como distribución de los recursos ${ }^{9}$, argumentando lo justo como el respeto a los derechos a la propiedad, a satisfacer las necesidades básicas y al derecho al trabajo.

La justicia como reconocimiento al "otro" en las interacciones cotidianas está referido fundamentalmente a la ausencia de agresión y la expresión del afecto ("Justicia es no maltratarnos a los niños; justicia es cuando las personas que me quieren y me aprecian me lo dicen"); al merecimiento ("La profesora le pone bien a unos niños sin merecerlo porque les tiene rosca, es muy injusto"); a la credibilidad y la confianza ("Es injusto cuando a una mujer la culpan de tener un hijo diferente del de su esposo y eso es mentira"); y al altruismo, la generosidad y la cooperación ("Cuando una persona intenta ayudar al barrio, hace justicia, como un muchacho que siempre recoge la basura; es injusto cuando los pobres piden ayuda y no se les escucha"); es decir, el reconocimiento es concebido por los niños y las niñas desde una perspectiva psicosocial.

\footnotetext{
${ }_{7}^{7}$ Concepciones politicas y transformación de actitudes frente a la equidad en niños y niñas de sectores de alto riesgo social del Eje Cafetero (reseñada en la nota de pie de página número. 1). Participaron en el estudio 36 niños y niñas en calidad de multiplicadores en sus escuelas, desarrollando la propuesta Niños y niñas constructores y constructoras de paz con 195 niños y niñas de 8 a 10 años.

${ }^{8}$ Un análisis detallado de estos resultados aparece publicado en la Revista Latinoamericana de Ciencias Sociales, Niñez y Juventud, Vol. 3, N. ${ }^{\circ}$ 2, julio-diciembre de 2005.

${ }^{9}$ El concepto de justicia como equidad en la redistribución y el reconocimiento es tomado de Fraser (2003).
} 
El reconocimiento a la dignidad humana es entendido como reconocimiento a sus derechos como seres humanos ("Es respetar y hacer respetar los derechos de los niños como personas, que los niños no tengan que trabajar descalzos"); como respeto al derecho a la vida, independientemente de cualquier circunstancia ("Es no matar a las personas ni a los niños; cuando a alguien lo violan y lo suicidan") o en relación con algún marco normativo ("No se debe matar porque es pecado"); como honestidad en las interacciones cotidianas y como pauta de comportamiento ("Cuando en un partido cometieron una falta en el área del penalti y el árbitro la pitó"); y como respeto al derecho a la libertad ("Si a uno lo obligan a casarse con otro hombre que uno no quiere debemos pedir nuestros derechos, pedir justicia").

El reconocimiento como no discriminación es interpretado como igualdad de oportunidades y de condiciones para la vida en común, con un concepto distributivo, no de los bienes, sino de las oportunidades para acceder a deberes, a derechos y a lo que se derive de ellos en términos legales, afectivos, de interacción social, de servicios, de participación ciudadana, etc. ("Dar a todos las mismas oportunidades y darle la razón al que la tiene; es que todos tengamos los mismos derechos y la misma ley").

La justicia como redistribución de recursos, entendida como derecho a la propiedad, es entendida como distribución equitativa de la riqueza y los bienes ("Tener la riqueza entre todos en un país; mejor dicho, que no hayan tan poquitos ricachones y tantos pobres"); señalan como injusto el hecho de quitar a alguien lo que le es propio, no sólo como falta moral, sino respecto a su relación social con la violación al derecho a la propiedad, argumentando dos tipos de razones, unas más ligadas a las consecuencias del hecho ("Es cuando un ladrón roba a un señor y es tan de malas que viene la policía y coge al ladrón y le toca devolver lo que robó"); y otras referidas a la identificación de lo justo con el cumplimiento de la norma ("Es cuando un señor se está robando una moto y la policía lo ve y lo coge, y esto es justo porque está prohibido robar"); interpretan como justo el hecho de robar cuando se hace para satisfacer necesidades básicas ("Es justo que la gente que no tiene hogar tiene que robar para poder comer y comprar ropa").

La justicia como derecho a satisfacer las necesidades básicas es argumentada por los niños y las niñas como derecho a la alimentación ("Cuando hay que comer"); a la recreación ("Es tener oportunidad de practicar el deporte honrado"); a tener un hábitat sano ("Que arreglen los baños"), a la salud ("Que todos tengamos oportunidad de la salud"), a la educación ("Que todos podamos ir a la escuela") y al vestido ("Es justo que las personas tengan en cuando sea que ponerse para salir").

La justicia como derecho al trabajo es argumentada tanto en términos del acceso y las condiciones ("Trabajo para todos; es injusto que los niños trabajen descalzos"), como de la remuneración por lo realizado ("Cuando lavo un carro y me pagan; que no le roben el salario a los trabajadores").

En la perspectiva jurídica y moral el $82 \%$ asocia la justicia con la aplicación de las sanciones por medio de la penalización de la falta; la retaliación, 
la venganza y el ajusticiamiento; y la inculpación a terceros. El 18\% restante asocia la justicia con el cumplimiento de la norma ${ }^{10}$, argumentando lo justo como cumplimiento de la ley, obediencia al adulto y comportamiento responsable.

La justicia como penalización de la falta a través de las sanciones o castigos y como expresión de no impunidad es argumentada en tres sentidos: justicia como sanción penal por parte del Estado ante el incumplimiento de las normas acordadas para la convivencia ciudadana ("Un señor se roba un banco y lo meten a la cárcel"); ante las violaciones al derecho a la vida ("Por mi casa mataron a dos hermanos y se volaron y deben meterlos a la cárcel"); ante actos delictivos ("A una niña que ha sido violada y al violador lo han encarcelado"); y ante comportamientos que hacen daño a otros ("Había una señora que tuvo un niño y el papá se separó de ella y ella lo demandó porque no le estaba pasando nada al niño y allá en la comisaría de familia obligaron a que le pasara la plata y se hizo justicia"); justicia como no impunidad, como ejercicio de la sanción, independientemente del papel del Estado ("Castigar a las personas como lo merecen, con el debido castigo"); y justicia como premio o reconocimiento al deber cumplido ("Cuando premian a alguien que hizo sus deberes y no solo castigan a los necios"). La justicia como retaliación y ajusticiamiento, como aplicación de la sanción ejercida directamente por la sociedad civil o por grupos humanos, ante la incapacidad del Estado o de la autoridad, está argumentada en dos tendencias: como venganza ("Un taxista mató a un muchacho que le andaba robando el pasacintas, y eso es justicia porque se lo tenía bien merecido, por ladrón”); y como defensa por las vías de hecho ("Justicia es hacer lo que se debe hacer a los demás para defenderse uno mismo o por la familia"). La justicia como no inculpación a terceros para librarse de la propia culpa en la violación de una norma, desplazando su responsabilidad a otros, para que sobre ellos recaigan las consecuencias punitivas del hecho, es argumentada tanto desde la deshonestidad ("Es algo que es malo porque en eso alguien sale pagando los platos rotos"), como desde el autoritarismo ("Mi mamá que me da una 'pela' y yo no fui y ella ni me pregunta").

La justicia como cumplimiento de la norma y de la ley va más allá de sus contextos primarios de interacción en la familia y la escuela, y es incondicional al contenido, al proceso de formulación o a los fines que persigue. Las normas y las leyes son buenas y legítimas por principio ("Las normas se deben cumplir, pues porque por eso son normas"). La legitimidad sólo es puesta en cuestión por los niños y las niñas cuando se refieren al hecho de matar; se reconoce que la ley lo prohibe, pero algunos niños y algunas niñas condicionan su justificación a la legalidad y la legitimidad de los actores sociales involucrados y a sus fines: es injusto matar a representantes de entidades legalmente establecidas del Estado ("Es una injusticia matar soldados que están defendiendo la patria"); es injusto el hecho de que maten las organizaciones establecidas ilegalmente ("Injusticia es que la guerrilla mate y destroce a los campesinos"); pero es justo matar cuando lo hacen organizaciones establecidas legalmente ("Como

${ }^{10}$ El concepto de justicia como cumplimiento de la norma y aplicación de la sanción se acerca más a la propuesta contractualista de Rawls sobre la justicia $(1996,1997)$. 
el presidente que para hacer la justicia hace guerra"). Los niños y las niñas justifican como justo el hecho de matar cuando existe un motivo o causa: ("Cuando la policía mata a los desechables y a los ladrones para limpiar la sociedad"). La justicia como obediencia al adulto, como cumplimiento a las expectativas que adultos significativos, padres y profesores, cuya autoridad consideran legítima, tienen sobre sus comportamientos y sus actitudes ("Actuar correctamente de acuerdo con lo que los otros esperan de mí, especialmente mi mamá"). Las justificaciones para obedecer están relacionadas con el temor al castigo ("Es ser ordenado... para no hacer rabiar a los papás para que no nos castiguen"), la gratitud y el cariño ("Yo he visto niños muy justos, buenos y educados que no meten droga para no hacer sufrir a su familia"), y con motivaciones religiosas ("Uno siempre va a la iglesia, obedece los mandamientos, no pelea, para no pecar"). La justicia como comportamiento responsable por parte de los niños, los adultos, las instituciones, no hace referencias explícitas a la norma o a la ley, sino, por el contrario, pone el peso del argumento en el sujeto ("Es que uno sea responsable; para mi la justicia es que los doctores actúen responsablemente").

En la perspectiva política el $75 \%$ asocia la justicia con la construcción de paz, interpretada por los niños y las niñas, como hecho político, como acto de conciencia individual y como ausencia de violencia en la vida cotidiana. El 25\% restante asocia la justicia con el ejercicio de la política y de la legalidad en un contexto democrático, argumentando lo justo como acción política orientada al bien común y como ejercicio de la función legal por parte del Estado.

La justicia como hecho político es argumentada a través de dos tendencias: la paz como un hecho universal que es expresada en declaraciones abstractas, sobre la paz como hecho universal, como un estado o situación deseable, cuya construcción nos corresponde a todos los ciudadanos, y frente a la cual los niños y las niñas se perciben como víctimas de la violencia y la guerra que se intentan superar, y no como partícipes en su proceso de construcción ("Que todos tengamos paz y que en el país no debe haber violencia porque los niños así no podemos ser felices"); y la construcción de paz como responsabilidad del Estado, donde se legitima el uso de la fuerza armada como condición para lograr el bienestar de los ciudadanos ("Todo lo que el gobierno hace contra la guerrilla y los paramilitares es justo, porque matan, violan, cometen secuestros y eso es malo"). Los niños y las niñas, al argumentar la justicia como proceso de construcción de paz que depende de la conciencia y la voluntad individual, no se refieren a las raíces estructurales de la violencia y de la guerra en los ámbitos social, económico, cultural y político, sino que ponen toda la responsabilidad de la construcción de la paz en el sujeto individual, como un problema de "buena conciencia" y de disposición favorable desde la voluntad, sin mediación de la acción política ("Si todos nos volviéramos buenos habría paz y eso sería la justicia"). La última tendencia se refiere a sus argumentaciones sobre la justicia como superación de la violencia cotidiana en sus escenarios de realización humana ("es que no atraquen, no trafiquen, no violen por el vicio; es injusto que los adultos nos den malos ejemplos con el sexo y nos hagan hacer cosas que a nosotros no nos gustan”). 
Según los niños y las niñas, la justicia, como acción política orientada al bien común involucra a diferentes actores sociales: por una parte, el Estado, que debe ejercer su autoridad para lograr condiciones de paz y justicia en el país ("es la respuesta del Estado ante las necesidades de los campesinos; es que se hagan leyes para que la riqueza de nuestro país sea para todos"); y, por otra parte, la sociedad civil, que debe participar de manera organizada en los procesos democráticos facilitados por el gobierno o desde la oposición ("Trabajar por el país cooperando con lo que nos conviene a todos"). Finalmente, los niños y las niñas argumentan la justicia como ejercicio de la función legal por parte del Estado, en el sentido de su responsabilidad en formular las leyes y en la necesidad de organizarse y de organizar a la sociedad para hacerlas cumplir ("La justicia son las leyes que representan a un país y las condenas que se ponen para las personas que no las cumplan").

Como lo muestran los resultados expuestos, la perspectiva social y cultural es, en primera instancia, la más fuerte en las concepciones de los niños y las niñas sobre la justicia, y corresponde a su interpretación de la justicia en términos de equidad referida en la gran mayoría de las oportunidades, al reconocimiento, en la acepción de Fraser, pero, a diferencia de su teoría, que pone el énfasis del reconocimiento en la inclusión cultural, los niños y las niñas lo ponen en lo que podríamos llamar "inclusión afectiva", pues definen los actos justos principalmente en los procesos de interacción cotidiana, ligados al afecto.

En segunda instancia, está la perspectiva moral y jurídica, en la cual los niños y las niñas argumentan sus concepciones de justicia ligadas a la categoría cumplimiento de las normas y sanciones, acercándose más a la propuesta contractualista de Rawls, pero poniendo la fuerza de sus argumentaciones no en la adhesión a la norma y en el respeto a las leyes y los acuerdos pactados, sino en argumentos que refieren la justicia al castigo, a la sanción ante el incumplimiento de la norma, bien sea por medio de la penalización de la falta por parte de la autoridad, o bien por medio de la retaliación o de la inculpación.

Aunque en pocos casos los niños y las niñas se acercan a una concepción de la justicia, más ligada, desde una perspectiva política, al ejercicio de la democracia, la mayor parte de los argumentos están ligados a la construcción de condiciones de equidad, inclusión y paz, como hechos políticos orientados al bien común.

Estos sentidos infantiles sobre lo justo y lo injusto se corresponden con las maneras prácticas y con los discursos, que las instituciones más cercanas (familia, escuela) agencian, pero a su vez son expresiones de los imaginarios sociales, que han despolitizado la "acción política", reduciendo las consideraciones sobre lo justo y lo injusto a los ámbitos privados, individuales (reconocimiento por medio de la inclusión afectiva) o a los discursos y las prácticas sociales punitivos (aplicar las sanciones). Algunos estudios sobre socialización política en la Hungría poscomunista muestran cómo en las concepciones de niños, niñas y jóvenes 
sobre la política prevalecen las valoraciones y las prácticas de la sociedad en su conjunto, en este caso, una democracia mínima, más ligada al sostenimiento del statu quo (Zsigo, 2003).

\section{A manera de conclusión}

En los imaginarios sociales la política se ha ido banalizando progresivamente y se ha ido haciendo precaria. La precariedad de la política se expresa en la gran frustración, la desconfianza social y la impotencia política que sienten las personas al no entender lo que pasa y al no encontrar poderes claros que orienten la vida en común y que les permitan dar sentido a su historia; las personas no pueden explicar ni por qué el país está como está o por qué hay violencia, por qué suben los impuestos, por qué la reelección, por qué la guerra, ni pueden explicar por qué no pueden acceder al trabajo, a la salud, a la educación, a la información, a responder a sus necesidades personales en la vida cotidiana. La banalización de la política se ve en su repliegue de los espacios públicos, en su desplazamiento al ámbito de lo privado e individual, en su reducción al ámbito de lo social-cultural, en el desplazamiento de las preguntas fundamentales por la injusticia social, preguntas que han ido quedándose en la añoranza de algunos intelectuales de izquierda. Hoy la construcción de democracia, de un orden social más justo, se plantea desde marcos que se agotan en lo jurídico-moral, desde una perspectiva individual más cívica que ciudadana, y desde posiciones que reivindican culturalmente a la persona desde su condición identitaria y no desde su configuración como sujetos políticos.

Los procesos de socialización política de niños y niñas tienen que enfrentar este reto. ¿Cómo apuntarle realmente a la configuración de sujetos políticos? ¿Cómo desencadenar procesos en los cuales dicha subjetividad política pueda desplegarse? En Colombia y en toda América Latina está impulsándose un amplio movimiento por la "formación ciudadana" desde la escuela. Tal vez allí podamos encontrar el escenario para poner en juego estos procesos, siempre que se parta de una posición crítica, política y no reducida a los acuerdos cívicos para la convivencia.

La formación ciudadana (socialización política) de niños y niñas tiene que articularse en procesos de reconfiguración de sus sentidos y sus prácticas en torno de la equidad y la justicia social (Lechner, 1999), y estos sentidos implican procesos de autorreflexión sobre: la conformación de confianza social, representada en la consolidación de lazos de cooperación que niños y niñas pueden establecer; la puesta en marcha de las normas de reciprocidad que superen la discriminación y la desigualdad en sus contextos primarios de actuación (familia, escuela y barrio); y, por último, la construcción de redes de acción social y política (en el sentido de orientarla colectivamente, al bien común) que ofrezcan escenarios y oportunidades en los cuales niños y niñas puedan desplegar su subjetividad política, como ciudadanos plenos. 
Es decir, que la formación ciudadana (socialización política) no se relaciona con los discursos y las prácticas de adhesión a los sistemas políticos formales (por ejemplo, comportamiento de voto), sino a la configuración de subjetividad política, en procesos que aproximan los sentidos y las prácticas de acción política en sus contextos de actuación a un orden social democrático, tanto en el ámbito microdimensional como en el macrodimensional, regido por principios de igualdad, justicia y libertad, en escenarios de pluralidad centrados no en la diferencia, sino en la distinción, en el reconocimiento de la diversidad de las múltiples condiciones identitarias que representan los yoes que se recuperan y se explicitan en la constitución de subjetividad.

En este sentido, la acción política es asumida por los individuos como la capacidad de afectar y participar en una construcción social (Lechner, 1999), que guarde más relación con el vínculo social que con los sistemas políticos; que le apueste a una clara adhesión a la democracia; basada en procesos organizados y colectivos de confianza social y de reciprocidad; que recoja dimensiones del ámbito privado, pero que no se reduzca a él; con énfasis en la participación en organizaciones sociales. Es decir, la socialización política, como práctica social, sólo puede darse en el ámbito de la colectividad y de los intereses sociales.

Bibliografía

Ackerman, L., Feeny, T., Hart, J., y Newman, J. (2003). Understanding and evaluating children's participation. $A$ review of contemporary literature. London: Plan International, U.K.

Berger, P., Luckman. T. (1995). Modernidad, pluralismo y crisis de sentido. Barcelona: Paidós.

$$
\text { (1983). La construcción so- }
$$
cial de la realidad. Buenos Aires: Amorrortu.

Collomb, R., Nathalie, N. (2003). Young people and citizenship: A comparison between Belfast and Marseille (Northern Ireland, France). Queen's University of Belfast UK. Proquest digital dissertations. wwwlib.umi.com/ dissertations/fullcit/3103037
Cubides, H. (2004). Formación del sujeto político. Escuela, medios y nuevas tecnologías de la comunicación y la información. En M. C., Laverde, G. Daza, y M., Zuleta. Debates sobre el sujeto. Perspectivas contemporáneas. Bogotá: Siglo del Hombre Editores.

Cussianovich, A., Márquez, A. (2002). Toward a protagonist participation of boys, girls and teenagers. Lima: Save The Children.

Chaffee, S., Morduchowitz, R., Galperin, H. (1997). Education for democracy in Argentina: Effects of a newspaper-in-school program. International Fournal of Public Opinion Research, 9.

Fraser, N. (2003). Redistribución, reconocimiento y exclusión social. En Inclusión y nuevas ciudadanías. Condiciones para la convivencia y seguridad democráticas. Seminario Internacional. Memorias. Bogotá: Pontificia Universidad Javeriana-DABS. 
González, F. (2002). Sujeto y subjetividad. Una aproximación histórico-cultural. Ciudad de México: Thompson.

Hart,J. (2004). Beyond struggle and aid: Children's identities in a Palestinian refugee camp. En J. Boyden, J. De Berry (Eds.), Children and youth on the front line: Ethnography, armed conflict and displacement. Oxford: Berghahn Books.

$\rightarrow$ (2004). Children's participation in humanitarian avtion: Learning from zones of armed conflict. Synthesis report and three country studies prepared for the Canadian International Development Agency (CIDA). Oxford: Refugee Studies Centre, University of Oxford and The International NGO Training and Research Centre, Intrac.

(2000). Children's clubs: New ways of working with conflict-displaced children in Sri Lanka. Forced Migration Review, 15.

Hart, R. (2000). Community governance and children's rights. En R. Ranjai (Ed). The political participation of children. Harvard Center for Population and Development Studies.

(1997). Children's participation: The theory and practice of involving young citizens in community development and environmental care. London: Unicef.

(1992). Children's participation: From tokenism to citizenship, Innocent essays, No. 4. Florence, Italy: Unicef International Child Development Centre.

Schwab, M. (1997). Children's rights and the building of democracy: A dialogue on the International Movement for Children's Participation. Social fustice, 3 (24). ERIC NO: EJ560363.

Jannings, L., O’Keefe, T. (2002). Parents and children inquiring together: Written conversations about social justice. Language Arts, 5 (79). ERIC N. ${ }^{\circ}$ EJ644852.
Jarés, X. (1999). Educación para la paz.

Madrid: Editorial Popular.

Lansdown, G. (2001). Promoting children's participation in democratic decision-making. En L. Ackerman, T. Feeny, J. Hart, J. Newman. Understanding and evaluating children's participation. A review of contemporary literature. London: Plan International, U.K.

Lechner, N. (1999). Las condiciones sociopolíticas de la ciudadanía. En Conferencia de clausura del IX Curso Interamericano de Elecciones y Democracia. Instituto Interamericano de Derechos Humanos-CAPEL e Instituto Federal Pectoral. Ciudad de México, 17-21 de noviembre de 1999.

Liao, H. (2003). Communication and political socialization: The case of kids voting western New York. State University of New York. Proquest digital dissertations. www.lib.umi. com/dissertations/fullcit/3111171

Maffesoli, M. (2004). Yo es Otro. En M. C. Laverde, G. Daza, M. Zuleta. (2004). Debates sobre el sujeto. Perspectivas contemporáneas. Bogotá: Siglo del Hombre Editores.

Martín, J. (2004). Crisis identitarias y transformaciones de la subjetividad. En M. C. Laverde, G. Daza, M. Zuleta. Debates sobre el sujeto. Perspectivas contemporáneas. Bogotá: Siglo del Hombre Editores. 
Ospina, H., Alvarado, S. (2001). Los niños, las niñas y los jóvenes recuperan su voz en los procesos de construcción de paz. Ponencia presentada en Encuentro Bilateral de Educadores y Comunicadores de Educación para la Democracia y la Paz. Lima.

Rawls, J. (1997). Teoría de la justicia. Ciudad de México: Fondo de Cultura Económica. ,(1996). Liberalismo político. Bogotá: Fondo de Cultura Económica.

Short, G., Carrington, B. (1991). Unfair discrimination: Teaching the principles to children of primary school age. Fournal of Moral Education, 2 (20). ERIC N. ${ }^{\circ}$ EJ48428.

Veloso, L. (2003). Remarking the future childhood and the paradoxes o citizenship in the Brazilian democratic imagination. University of Chicago. Proquest digital dissertations. www. lib.umi.com/dissertations/fullcit/3007167
Woodhead, M. (1998). Children's perspectives on their working lives. A participatory study in Bangladesh, Ethiopia, The Philippines, Guatemala, El Salvador y Nicaragua. Stockholm: Radda Barnen. , (1997). Psychology and the cultural construction of children's needs. En A. James, A. Prout (Eds.), Constructing and reconstructing childhood: Contemporary issues in the sociological study of childhood. London: Palmer Press.

Zemelman, H. (2004). En torno de la potenciación del sujeto como constructor de historia. En M. C., Laverde, G. Daza, M., Zuleta. Debates sobre el sujeto. Perspectivas contemporáneas. Bogotá: Siglo del Hombre Editores.

Zsigo, F. (2003). Democratic ideas, understandings, practices and attitudes among students in post-communist Hungary, 1989-2001. Syracuse University. Proquest digital dissertations. www.lib.umi.com/ dissertations/fullcit/ 